V. Aus der chirurgischen Privatklinik von P. Postnikow und G. Sumarokow in Moskan. \title{
Osteoplastische Radicaloperation der Spina
} bifida.

Von P. J. Postnikow.

Der als Spina bifida bezeichuete Entwicklungsfehler ist von Alters her bekannt, doch erst seit Beginn dieses. Jahrhunderts wurde dank den embryologischen Untersuchungen seine Pathogenese mehr nnd mehr geklärt, und damit gewann auch die Therupie naturgemäss an Zweckmässigkeit und an Erfolg. Ich will in nachstehender Mittheilung nur anf eine verhältnissmässig neue Behandhungsmethode der Spina bifida aufmerksan machen, nämlich anf die Deckung des Knochendefects durch Knochencewebe. Vor der blossen Idee. die Integrität des Knochencallals herzilstellen, kömmen alle anderen Behandlıngsmethoden nicht bestehen, sie müssen allmählich, je weiter sich die Radicaloperation entwickelt, immer mehr in den Hintergrund treten nnd schliesslich ganz der Geschichte anheimfallen.

Zum orsten. Mal wurde die Möglichkeit einer Knochenplastik von Käng angeregt. Im Jahre 1883 versuchte Robert Hayes, ${ }^{1}$ ) dann 1885 M. Robson einen Knochenversehluss des Defects zu exzielen, indem sie ihn nach Entfermung und Vernähung des Sackes mit Periost vom Kaninehen bedeckten; es wurden anch Versuche gemacht, den Defect dureh Knochen zul schliessen, der vom Thier geuominen war, und zwal durch ein Stück voul Schulterblatt eines jungen Kaninchens; ${ }^{2}$ ) Dollinger ${ }^{3}$ ) endlich entfernte an 25. November 1885 einen Theil des Sackes, vernähte ibn, schob ihn in den Knochencanal und vernähte über ihm die

1) Bellanger, Traitement de spina bifida. These de Paris 1891

2) Rochet, l. e.

3) Wiener nedicinische Wochensehrift 1886, No. 36. 
rudimentären Bögen des rierten und fünften Lendenwirbels, die vorleer eingebrochen und bis zur Berülurung einander' angenähert waren. Tas war die erste wirklich osteoplastische Operation der Spina bifida. Auf dem dritten Congress russischer Aerzte in Petersburg im Jalıe 1889 berichtete Senenko ïher cinen analogen Fall. Die Oeffinung war im erstem nnd zweiten Kreuzbeinwirbel. Nach Entfernmlng des Sackes wurden beiderseits die Rudimente der Bögen und der Hinterhöcker abgemeisselt, zur Mittellinie verschoben und vernältt, so dass ïber dem Canal eine knöcherne Bedeckumg von $4 \mathrm{~cm}$ Breite entstand. Das ist eine schöne, zweckmässige Operation, doch ist sie nicht in allen Fällen ansführbar. Linmal können die Bögen so wenig entwickelt sein, dass man sich ilırer beim besten Willen nicht bedienen kann: ferner wird bein Anıälıern der Wirbelbögen zum Zweck der Naltt das I umen des Wirbelcanals verkleinert, was hïufir unerwünscht ist, namentlich wenn der Sack so klein ist, dass man ihn nicht zu exstirpiren brancht, sonder'n in den Knochencanal hineinstiilpen kann. Das ist natïrlich immer anzustreben. denn wenn man den Sack exstirpirt, schneidet man jedesmal anch Nervenfisern heraus. Zwar wissen wir, dass diese Fasern meistentheils mir dem äısseren Anselien nach Nervenfasern sind und dass der Kranke durch ihre Entfernung in der Regel nichts verliert, doch diirfen wir nicht vergessen, dass das eben nur meistentheils der Fall ist, keineswegs immer; da wir aber dnrch den blossen Anblick während der Operation nicht imstande sind, den Charakter' dieser Fasern zu bestimmen, dabei aber der physiologisch wichtigen Bedentung der Ritckenmarksfasern stets eingerlenk sein miissen, so ergiebt sich von selbst die Frage, ob wir berechtigt sind, Hand an sie zu legen. Jedes Nervenfäserchen erfordert Schomıng, somit anch der Sack. und nur im änssersten Falle dinfen wir ilın entfernen, weın el nümlich zu gross ist, nnd auch danu nur partiell, möglichist wenig, so dass er gerade im Knochencanal Platz findet. In solchen Fällen wird die Dollinger'sche Methodo nngeeignet erscheinen, da sie das Lumen des Canals verengt; hier gebührt der Vorzug unstreitig der Methode, welche Bobrow ${ }^{1}$ in Jahre 1892 voroeschlagen hat und deren ich mich im nachstehenden Falle bedient habe. Da bisher noch sellr wenige osteoplastische Operationeu dieser Art veröffentlicht sind, so laalte ich es für angezeigt, meinen Fall ausführlich zu beschreiben.

Der 4 jährige Andr. B ist das fünfte Kind gesunder Eltern: veder seine älteren zwei Brüder and zwei Schwestern, noch seine jüngere Geschwister (ein Bruder und eine Schwester) weisen irgend welche Entwicklıngsfehler auf. Zwei Geschwister sind am Scharlach gestorben, welchen anch alle iübrigen Geschwister durchgemacht haben, ausgenommen nnseren Patienten, der izberhaupt nie krank gewesen ist. Weder von Seiten des Vaters, eines kräftigen Mannes, noch auch seiten der völligr gesunden Mutter sind bei irgend jemand in der Verwandtschaft Missbildungen vorgekommen. Die Hebanme, welche bei der Geburt des kleinen Andr. anwesend war, rieth, zun Arzte zu schicken, da sie am nntersten Ende des Rückens bei dem Nengeborenen eine fast hïhnereigrosse, weiche, durchsichtige Geschwulst bemerkte, die an einem langen, dïnnen Stiel sass, als ob noch eine Nabelschnır da wäre", wie die Eltern sich ausdrückten. Der lerbeigeholte Arzt nuterband den Stiel und durchsclmitt ihn mit einer Scheere. Andere Abweichungen von der Norm wurden an dem Knaben nicht bemerkt. Er begann im vierten Mona u zahnen, wnchs und entwickelte sich ganz normal, nur am unteren Theil des Rückens blieb eine Geschwulst bemerkbar, welche besonders dan zll wachsen anfing, als der Kleine zll gehen begann. Am 18. März 1894 wurde er in insere Privatklinik gebracht. Bei der Besichtigung bemerkten wir hinten, entsprechend den unteren Lendenwirbeln nnd dem oberen Theil des Kreuzbeins, fast in der Mittellinie, eine rundliche Geschwıllst von der Grösse einer nicht zn kleinen Apfelsine; die bedeckende Hant ist voll ganz normalen Anssehen, inıd nur in der Mitte auf dem höchsten Punkt benerkt man ansnahmsweise eine narbige Einziehung, welche selır an einen Nabel erinnert. Beim Betasten macht die Geschwulst ganz und gar den Eindruck eines Lipoms; nur bei Drıck anf die nabelformig eingezogene Narbe fühlt man nnter der Geschwulst in ihrem Centrum die Anwesenheit von Flussigkeit; die ganze Lipommasse pulsirt, d. lı. sie erhält von der darunterliegenden Fliissigket eine pulsatorische Bewegung. Die Auscultation der Geschwulst ergiebt nichts. Druck bewirkt weder Schmerzen noch Verkleinerung der Gescliwulst, noch anch irgend welche nervösen Erscheinungen. Der Knabe sagt, die Gesclıwulst thne ihm nur dann weh, wenn ihn jemand daranf schlage. Bei Verschiebung der Geschwulst nnd Palpation der darunterliegenden Wirbelknochen tritt deutlich ein ziemlich bedeutender Knochendefect zil Tage. Unsere Diagnose lautet: Myelomeningocele, bedeckt von einem Lipoun. Da die Geschwulst in letzter Zeit merklicher zll wachsen beginnt, sich an einer sehr unbe"1'Aemen Stelle befindet und in Zıkkunft nicht nur störend, sondern aıcl gefährlich werden kann, wenn gewisse Zufälligkeiten eintreten, so beschlossen wir, operativ vorzugehen, und zwar sollte es wegen der Grösse der durchzufühlenden Knochenstïcke eine osteoplastische Operation sein

Am 19. März 1894 wurden in Chloroformnarkose auf dem Scheitel ler Geschwulst um die narbige Einziehung zwei halbmondförmige Schnitte geführt, nach links und rechts Hautlappen abpräparirt und dio Basis des Lijoms wurde freigelegt. Hierauf begann ich mit vorsichtigen Schnitten den sich aus dem Knochencanal hervordrängenden Sack von der Geschwulstmasse abzulösen. Als dieses geglitckt und das Lipom entfernt war, präsentirte sich eine kleine längliche Geschwulst mit ganı dünnen Wänden nnd flüssigem Inhalt. 'Die Oeffnung in der Wirbelsiinle ist eine recht ansehnliche: ca. $6 \mathrm{~cm}$ lang und iiber $2 \mathrm{~cm}$ breit. Der Sack selbst war nicht gross und liess sich sehr leicht in den Knochencanal schieben, wobei sich Fasern durchfï̈hlen liessen, die mit den Wänden des Sackes in Zusammenhang zu stehen schienen; deshalb beschloss ich, den Sack nicht zol exstirpiren, da hierbei Nervenfasern liätteıı durch- schnitten werden missen, soudern ibn zol reponiren und den Knochendefect, wolcher den vierten nud fïnften lenden- und den ersten Krenzbeinwirbel betraf, durcl Kuochenplastik vom Os ilej ans zn decken; zn diesem Zweck führte ich von der Mitte des Sclnnittes aus einen zweiten nach links und nnten, und zwar oberhalb der Spina superior posterior. Von der Squanıa ossis ilei löste ich nnterhalb der Crista die Ansatzstelle des Glutaeus magnins nnter Schomnng des Periosts $a b$, umschriel mit dem Messer ein Knochenstiick von erforderlichler Grösse (dem Defect entspreshlend) und meisselte es ab. Dieses Knochenstiick, welches an einer Seite vom Periost bedeckt, war, wurde an inneren Rande mit den Weichtheilen in Verbindung belassen, d. l. hanptsiichlich mit den Faseln

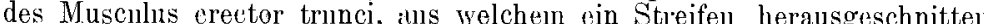
wurde, der von dem abgelösten Kunchenstïck in der Richltung zum Defect ging, nnd anf diesem Streifen wurde das Kinoclienstiick so anf den Defect gestiilpt, dass das Periost nach innen in den Wirbelcanal zu liegen kam, wïlırend die Sclunittfläche ihr spongioses Gewebe nacl anssen kehrte; sodann sclunitt ich mit dem Messer die Enden der rudimentären Bögen des vierten I.enden- and ersten Kreuzbeinwirbels and nältte mit vier Seidennähten, jederseits zwei, die Knochenplatte an. Dann wurde die Wunde geschlossen und rerbunden. Nach der Operation keinerlei unangenehme Nebenerscheinungen. Keine Klagen. Am achten Tage wurden die Hautnähte entfernt. Durchweg prima intentio. Nach der Operation vergingen bloss zwei Wochen, die der Junge geduldig und gewissenhaft auf dem Rücken liegend zubrachte, als ich die Möglichkeit hatte, ibn der Gesellschaft russischer Aerzte in Moskau zı demonstriren. $\mathrm{Er}$ war damals nitiinllich noch etwas schwach, sein Gang machte einen etwas atactischen Eindritck, besserte sich aber voll Tag zu 'T'ag so sehr, dass ich den Knaben genan drei Wochen nach seinem Eintritt in unsere Klinik in seine Heimath, nach Minsk, entlassen konnte. Zwei Wochen später erhielt ich vinen Brief nit der Mittheilung, dass der Knabe völlig genesen sei.

Diese Operationsmethode hat meiner Ansicht nach entschieden eine Znkunft: sie wird läufige Anvendung finden bei Spina bifida sacralis, sacro-lımbalis und auch lımbalis, denn aus dem Os ilei kann man immer ein Knochenstiick von jeder beliebigen Form und Grösse entnehnen, ebenso wie man anch aus den langen Rückenmuskeln ein Stïck von beliebiger Grösse heranslösen kann. Als Professor A. Bobrow seine Mittheilıng machte und dabei den in (ler Genesung befindlichen Kranken demonstrirte. $\left.{ }^{1}\right)$ da meinte er, man könnte bei der seltener vorkomnıenden Spina bifida des oberen Absclınitts der Wirbelsänle Knochenplisttchen von den Rippen benutzen. Anch von der Scapula kann geeignetes Material zur Knochenplastik gewonnen werden (N. Sklifoss of ky).

Es ist zn hoffen, dass die osteoplastische Radicaloperation der Spina bifida in naheliegender Zeit die ansgedelmte Anwendung finden wird, welcho sie verdient, und wenn sie dann noch, was durchans wünschenswerth ist, bei Kindern im ersten Lebensjalıre ansgefïhrt werden wird, dann werden viele mit diesem Entwicklungsfehler geborene Kinder, die frülter nicht einmal das erste Jahr ibberlobten, ${ }^{3}$ ) sich als vollkommen lebensfähig erweisen, nnd nur eine nnbedeutende Narbe an Stelle der ehemaligen Missbildung wird Zengniss ablegen von den Errungenschaften $d{ }^{2} \mathrm{r}$ modernen Chirurgie.

1) Chirmlgitscheskaïa Letopis 1892, 71,4 (Russiscll).

1) 274. Sitzıng der chirurgischen Gesellschaft zn Moskau, 11. Miirz 1892. 2) Von 642 mit Spina bifida geborenen Kindern starben 612 im ersten Lebcnsjahre. Londoner' Commission. 'The Lancet 1885. 